\title{
Establishment of an intermittent cold stress model using Tupaia belangeri and evaluation of compound C737 targeting neuron-restrictive silencer factor
}

\author{
Chi HAI-YING ${ }^{1,2)}$, Kiori NAGANO ${ }^{1,2)}$, Sayeh EZZIKOURI ${ }^{3)}$, Chiho YAMAGUCHI ${ }^{1,2)}$, \\ Mohammad Enamul Hoque KAYESH ${ }^{2}$, , Khadija REBBANI ${ }^{2)}$, Bouchra KITAB ${ }^{2)}$, \\ Hirohumi NAKANO ${ }^{5}$, Hiroyuki KOUJI ${ }^{5)}$, Michinori KOHARA ${ }^{6}$, and \\ Kyoko TSUKIYAMA-KOHARA ${ }^{1,2)}$ \\ 1) Transboundary Animal Diseases Center, Joint Faculty of Veterinary Medicine, Kagoshima University, 1-21-24 \\ Korimoto, Kagoshima-city, Kagoshima 890-0065, Japan \\ 2) Laboratory of Animal Hygiene, Joint Faculty of Veterinary Medicine, Kagoshima University, Kagoshima, Japan \\ 3) Virology Unit, Viral Hepatitis Laboratory, Institut Pasteur du Maroc, Casablanca, Morocco \\ 4) The United Graduate School of Veterinary Science, Yamaguchi University, Yamaguchi 753-8515, Japan \\ 5) PRISM BioLab Co. Ltd., Kanagawa 226-8510, Japan \\ 6) Tokyo Metropolitan Institute of Medical Science, Tokyo 156-8506, Japan
}

\begin{abstract}
Previous studies have shown that intermittent cold stress (ICS) induces depression-like behaviors in mammals. Tupaia belangeri (the tree shrew) is the only experimental animal other than the chimpanzee that has been shown to be susceptible to infection by hepatitis $B$ and $C$ viruses. Moreover, full genome sequence analysis has revealed strong homology between host proteins in Tupaia and in humans and other primates. Tupaia neuromodulator receptor proteins are also known to have a high degree of homology with their corresponding primate proteins. Based on these similarities, we hypothesized that induction of ICS in Tupaia would provide a useful animal model of stress responses. We exposed young adult Tupaia to ICS and observed decreases in body temperature and body weight in both female and male Tupaia, suggesting that Tupaia are an appropriate animal model for ICS studies. We further examined the efficacy of a new small-molecule compound, C737, against the effects of ICS. C737 mimics the helical structure of neuron-restrictive silencer factor (NRSF/REST), which regulates a wide range of target genes involved in neuronal function and pain modulation. Treatment with $\mathrm{C} 737$ significantly reduced stress-induced weight loss in female Tupaia; these effects were stronger than those elicited by the antidepressant agomelatine. These results suggest that Tupaia represents a useful non-rodent ICS model. Our data also provide new insights into the function of NRSF/REST in stress-induced depression and other disorders with epigenetic influences or those with high prevalence in women.
\end{abstract}

Key words: compound C737, intermittent cold stress, NRSF/REST, Tupaia belangeri

\section{Introduction}

Tupaia belangeri, known as the tree shrew [6], belongs to the family Tupaiidae, which consists of 4 genera and 19 extant species [16]. Tupaia have been utilized in pre- clinical research, particularly in the fields of toxicology and virology, because of the high degree of genetic homology between several of their neuromodulator receptor proteins and those found in primates [8]. Tupaia have the potential to serve as animal models for various aspects of

(Received 14 December 2015 / Accepted 4 March 2016 / Published online in J-STAGE 4 April 2016)

Address corresponding: K. Tsukiyama-Kohara, Kagoshima University, 1-21-24 Korimoto, Kagoshima-city, Kagoshima 890-0065, Japan Abbreviations: $H C V$, hepatitis C virus; HBV, hepatitis B virus; ICS, intermittent cold stress; NRSF, neuron-restrictive silencer factor; i.p., intraperitoneally; REST, RE1-silencing transcription factor

(C)2016 Japanese Association for Laboratory Animal Science 


\begin{abstract}
1
Human: MATQVMGQSSGGGGLFTSSGNIGMALPNDMYDLHDLSKAELAAPQLIMLANVALTGEVNG Tupaia: MATQVMGQSSGGGGLFPSSGSLGMALPNDMYDLHDLSKAELAAPQLIMLANVALTGEVNG Mouse: MATQVMGQSSGGGSLFNNSANMGMALTNDMYDLHELSKAELAAPQLIMLANVALTGEASG
\end{abstract}

Fig. 1. Neuron-restrictive silencer factor/RE1-silencing transcription factor sequence alignment (amino acids 1-60) from Homo sapiens, Tupaia belangeri, and Mus musculus. Amino acids that differ from the human neuron-restrictive silencer factor/RE1-silencing transcription factor (NRSF/REST) sequence are shaded. The minimal repressor domain, which may contain a binding sequence for the paired amphipathic helix domains of $\operatorname{Sin} 3$ proteins, is highlighted in yellow. The Tupaia NRSF/REST sequence was predicted from whole genome sequences [32].

human behavior, including infant development, communication, and social structures [32]. In particular, chronic social stress in Tupaia belangeri is a natural and valid paradigm for studying behavioral, endocrine, and neurobiological changes that may underlie stress-related disorders such as depression [5-8]. Although adult male Tupaia exhibit strong territoriality in their natural habitat, two males in visual and olfactory contact in a laboratory establish a stable dominant-subordinate relationship, where subordinates show distinct stress-induced alterations in behavior, physiology, and central nervous system activity [9]. The alterations exhibited by subordinate male Tupaia are similar to those observed in depressed human patients; in fact, Tupaia have been shown to be an effective animal model for the evaluation of antidepressant drugs [26].

Tupaia belangeri chronic social stress model is a natural and valid paradigm for studying the behavioral, endocrine, and neurobiological changes that may underlie stress-related disorders, such as depression $[7,8]$. Intermittent cold stress (ICS) induced in mice is also used as a model of depression [22, 23]. ICS produces longlasting thermal hyperalgesia and mechanical allodynia, particularly in female gonadectomized mice [23]. The aims of this study were to evaluate a new ICS model using Tupaia and to characterize the role of a key transcription factor in depression. Neuron-restrictive silencer factor (NRSF), also known as REST (RE1-silencing transcription factor) [4], is a transcriptional repressor of neuronal genes in non-neuronal cells. NRSF/REST interacts with other proteins, including the corepressors mSin3a and CoREST1, to form REST repressor complexes [29]; these interactions may play a critical role in the regulation of central nervous system activity and pain modulation. An amino acid alignment of NRSF/REST sequences indicates that, although Tupaia NRSF/REST shows higher homology to human NRSF/REST than to the mouse protein, the minimal repressor domains that may play a significant role in the interaction of NRSF/
REST with mSin $3 \mathrm{~B}$ are completely conserved among the human, Tupaia, and mouse proteins (Fig. 1) [24].

To address the role of NRSF/REST, Kouji et al. have designed low-molecular-weight compounds that mimic the alph $\alpha$-helical structure of NRSF/REST [35], including C737 [10]. Based on known functions of NRSF/ REST, C737 is expected to affect the expression of multiple neuronal proteins, including ion channels [15] and neurotransmitter synthetases and receptors $[19,20]$. In this study, we aimed to evaluate the efficacy of C737 against ICS-induced weight loss and temperature changes in male and female Tupaia.

\section{Materials and Methods}

\section{Ethics statement}

This study was carried out in strict accordance with both the Guidelines for Animal Experimentation of the Japanese Association for Laboratory Animal Science and the Guide for the Care and Use of Laboratory Animals of the National Institutes of Health. All experimental protocols were approved by the institutional review boards of the regional ethics committees of Kagoshima University (VM12017, VM13043).

\section{Animals}

Young adult male or female Tupaia (aged 6 months, summarized in Table 1) were bred in-house at Kagoshima University. Experiments were carried out according to standard guidelines for Tupaia care and use.

\section{Drugs}

The compound $\mathrm{C} 737$ was designed and supplied by PRISM BioLab Co. (Yokohama, Japan). As a positive control, a group of animals was treated with the antidepressant agomelatine, a melatonin analogue that acts as an agonist for melatonin MT1 and MT2 receptors and a specific antagonist for serotonin (5-HT) $2 \mathrm{C}$ receptors 
Table 1. Summary of Tupaia used in this study

\begin{tabular}{lcccccc}
\hline & No. 40 & No. 35 & No.41 & No. 36 & No.42 & No. 39 \\
\hline Age & 6 Months & 6 Months & 6 Months & 6 Months & 6 Months & 6 Months \\
Sex & Male & Female & Male & Female & Male & Female \\
Treatment & \multicolumn{2}{c}{ C737 } & Agomelatine & 10\% DMSO in PBS(-) \\
\hline
\end{tabular}

[25]. C737 and agomelatine (Wako Pure Chemical Industries, Ltd., Osaka, Japan) were each dissolved in 10\% dimethyl sulfoxide (DMSO) in water and administered at $10 \mathrm{mg} / \mathrm{kg}$ ip.

\section{ICS exposure and drug treatment}

ICS exposure and constant cold stress were performed on 3 male and 3 female Tupaia (Table 1) according to previously described methods [22]. Body weight, rectal temperature, drink volumes, and behavior were recorded each day for 5 days. We then placed the animals at room temperature $\left(24 \pm 2^{\circ} \mathrm{C}\right)$ for $30 \mathrm{~min}$, followed by 4 $\pm 2^{\circ} \mathrm{C}$ for $30 \mathrm{~min}, 6$ times consecutively. Rectal temperature and body weight were measured during these procedures and each day for the following 4 days. After 2 weeks, the animals were divided into 3 groups $(n=2$ per group): a solvent control group (10\% DMSO in PBS[-]), a positive control group (agomelatine $10 \mathrm{mg}$ / $\mathrm{kg}$ ip), and a C737-treated group (10 mg/kg ip). Treatments were administered once per day for 5 days. ICS was then induced as above. Body weight and rectal temperature were measured during these procedures and each day for the following 4 days.

\section{Statistical analysis}

The Wilcoxon test was used to evaluate significant differences between groups. Statistical analyses were performed using GraphPad PRISM version 6.0e (GraphPad Software, San Diego, CA, USA). All $P$-values were two-sided and $P<0 \cdot 05$ was considered significant.

\section{Results}

Effect of C737 on outlook and neural behavior of the Tupaias

The small compound $\mathrm{C} 737$ was designed to mimic the helical structure of the NRSF [35], and was expected to affect different aspects of neuronal function, including ion channels [15], neurotransmitter synthetases [19], and receptors [20]. The alignment of NRSF/REST protein (amino acid 1-60) was performed (Fig. 1). Although
Tupaia NRSF shows higher homology with human molecule than mouse one, the minimal repressor domains that may play significant role for interaction with $\mathrm{mSin} 3 \mathrm{~B}$ are completely conserved among human, Tupaia and mouse (Fig. 1) [24].

We have evaluated the effect of $\mathrm{C} 737$ on their outlook and behavior of the Tupaias. The $\mathrm{C} 737$ administered intraperitoneally at $10 \mathrm{mg} / \mathrm{kg}$ caused no neural or other toxic effects in male or female Tupaias, and they did not show any abnormal food intake, expression, or behavior. The positive control is the antidepressant drug, agomelatine [25]. Agomelatine is a melatonin analogue that acts as an agonist for melatonin MT (1) and MT (2) receptors, and as a specific antagonist for 5-HT (2C) receptors. Administration of agomelatine did not cause neural or other toxic effects in the Tupaias.

\section{Treatment of intermittent cold stress in Tupaia belangeri}

ICS produces long-lasting thermal hyperalgesia and mechanical allodynia, predominantly in female gonadectomized mice [23]. Therefore, we applied ICS to 3 males and 3 females Tupaia (Table 1). We first brought them from room temperature $\left(24 \pm 2^{\circ} \mathrm{C}\right)$ for $30 \mathrm{~min}$, to $4 \pm 2{ }^{\circ} \mathrm{C}$ for $30 \mathrm{~min}, 6$ times consecutively (Fig. $2 \mathrm{~A}$ ). During these stresses, we measured body temperature and body weight, and indicated a compound untreated control in Figs. 2 and 3. After 2 weeks, the Tupaias were divided into 3 groups, solvent control group (10\% DMSO in $90 \%$ PBS $(-)$ ), positive control group (agomelatine $10 \mathrm{mg} / \mathrm{kg} / \mathrm{ip}$ administrated), and C737 (10 mg/kg/ip) treated group (Fig. 2B).

\section{Effects of C737 and agomelatine on Tupaia behavior following ICS}

To evaluate the effects of $\mathrm{C} 737$ and agomelatine on ICS, each drug was administrated at $10 \mathrm{mg} / \mathrm{kg}$ ip each day for 5 days before ICS treatment. Neither drug caused neural or toxic effects nor resulted in abnormal food intake, expression, or behavior in male or female Tupaia. In female Tupaia, ICS-induced body weight decreases were prevented more effectively by $\mathrm{C} 737$ treatment (Fig. 
(A)

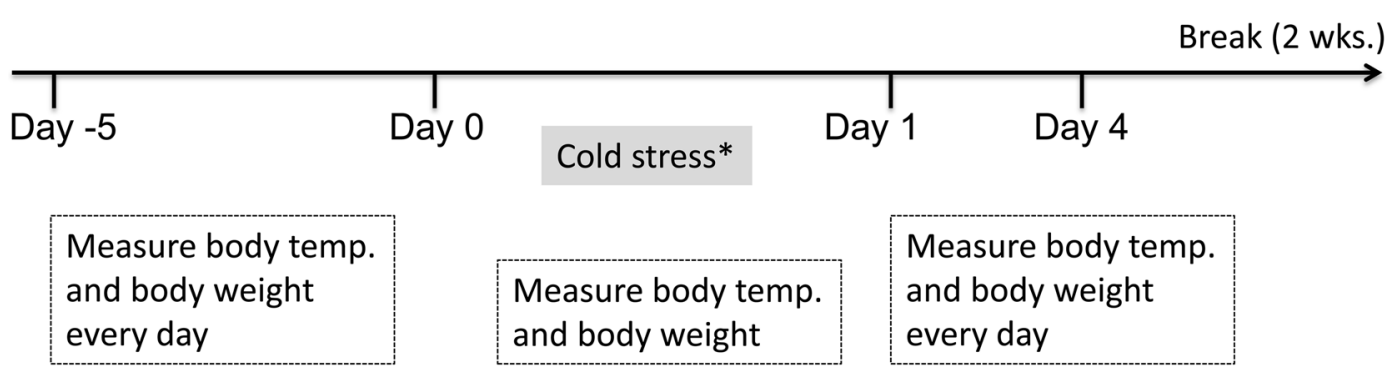

(B)

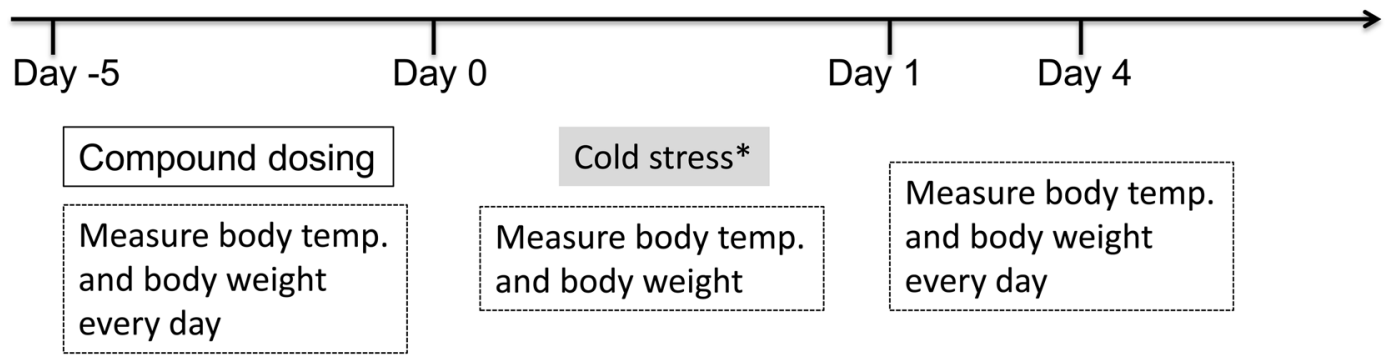

Fig. 2. Experimental design for intermittent cold stress and drug treatments. (A) Body temperature and body weight of each animal were measured for 5 days before intermittent cold stress (ICS) induction. ICS treatments were repeated 6 times; body weight and temperature were measured during and after ICS. (B) Animals were then treated with C737, agomelatine, or solvent control once per day for 5 days and then exposed to ICS. Body temperature and body weight were measured throughout the experiment.

3B) than by agomelatine treatment (Fig. 3D), although both treatments prevented weight decreases more effectively than the solvent control (Fig. 3F). Pre-treatment with $\mathrm{C} 737$ or agomelatine showed no significant effects on ICS-induced decreases in body temperature (Figs. $3 \mathrm{~A}, 3 \mathrm{C}$ and $3 \mathrm{E})$.

In male Tupaia, ICS-induced decreases in body temperature were more pronounced in the $\mathrm{C} 737$ and agomelatine-treated animals after 6 cold treatments, respectively (Figs. 4A and 4C). C737 was more effective than agomelatine at reducing ICS-induced weight loss (Figs. 4B and 4D); however, its effects were similar to those observed in the solvent control-treated animal (Fig. 4F).

\section{Discussion}

Non-rodent animal models may be used to characterize the molecular mechanisms of neurological diseases with epigenetic influences such as depression and to effectively evaluate treatments. Tupaia belangeri was previously classified as a primate but is now classified within the order Scandentia [36] and family Tupaiidae.
Tupaia have been used in the characterization of social stress [8], depression [7], and for the evaluation of antidepressant drugs [26]. In the present study, treatment with the antidepressant agomelatine partially prevented ICS-induced decreases in body weight in a female $T u$ paia; however, this effect was more pronounced in an animal treated with $\mathrm{C} 737$.

The inhibitory effects of $\mathrm{C} 737$ and agomelatine on ICS-induced weight loss were observed only in female Tupaia. Interestingly, ICS induces painful effects similar to those of fibromyalgia, a disorder that primarily affects women [33]. Consistent with this pattern, ICS-induced allodynia is more commonly observed in females in a gonadectomized mouse model of fibromyalgia [23]. The exact molecular mechanism responsible for these effects should be addressed in future studies.

NRSF/REST is a transcriptional repressor of more than 1,000 neuron-specific genes in mammalian non-neuronal cells [3, 28]. Many target genes of NRSF/REST [30] encode proteins with neuronal functions, including ion channels (e.g., sodium channel type II [15]), neurotransmitter synthetases (e.g., choline acetyltransferase [18, 19] and 
(A) Body Temperature

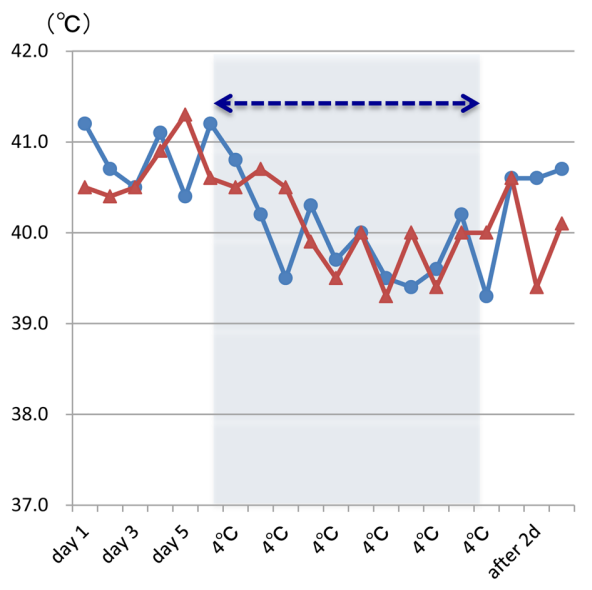

\section{(C) Body Temperature}

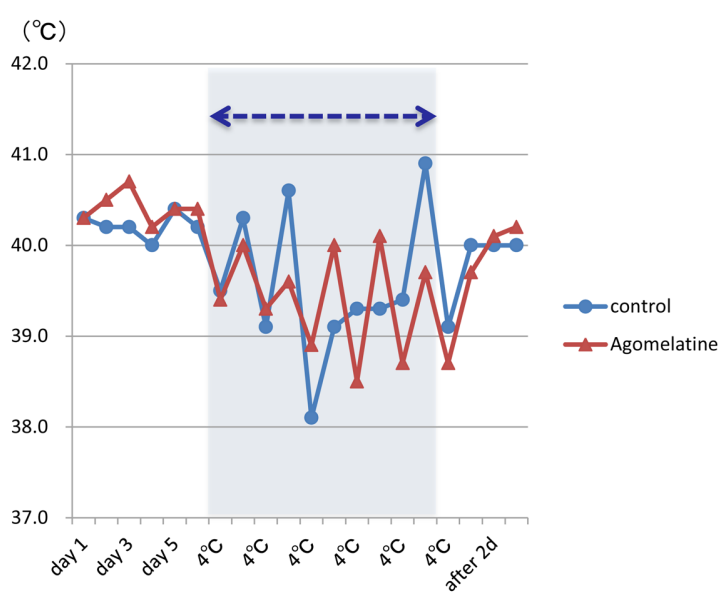

(B) Body Weight

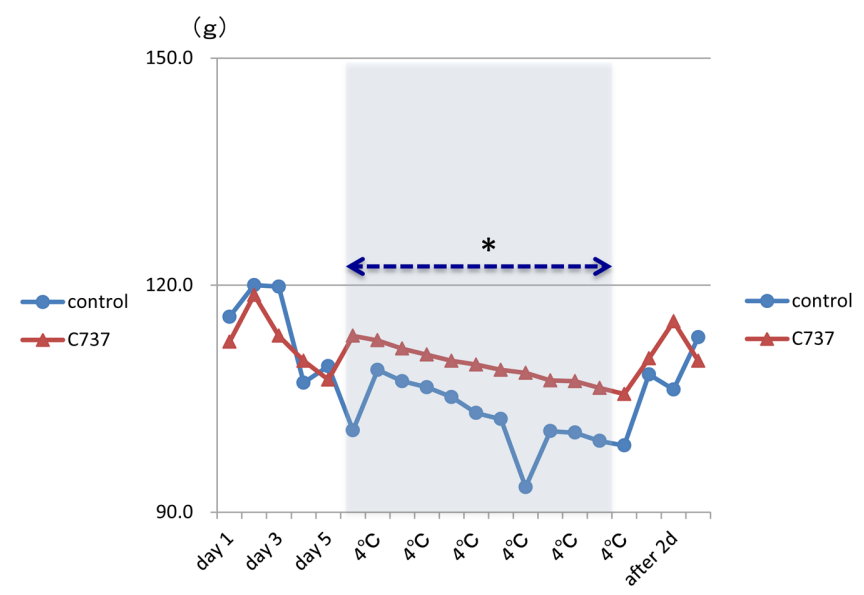

(D) Body Weight

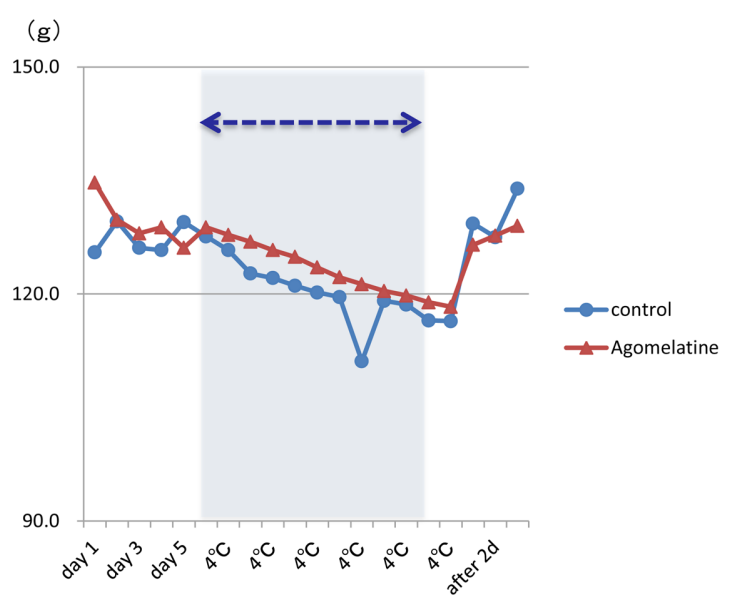

(F) Body Weight

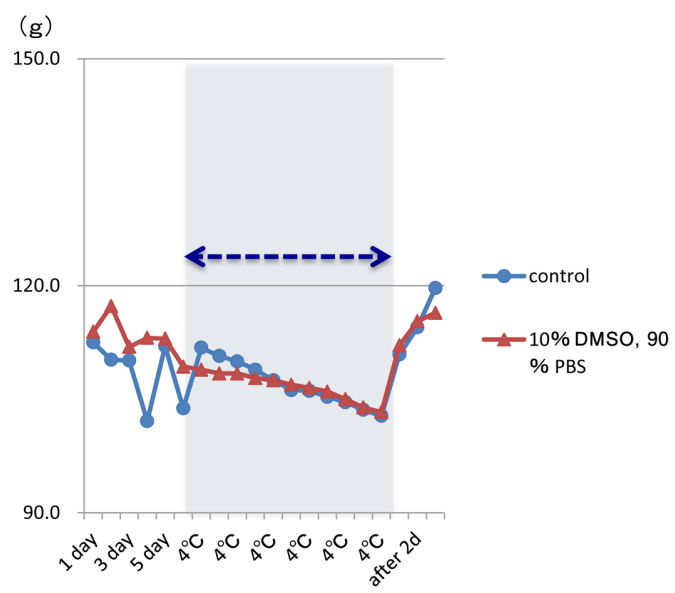

Fig. 3. Changes in body weight and body temperature in ICS-exposed female Tupaia. Body temperature (A, C, E) and body weight (B, D, F) of female Tupaia exposed to ICS with and without pre-treatment with C737 (animal No. 35; A, B), agomelatine (No. 36; C, D), or solvent control (No. 39; E, F). Shaded regions and arrows indicate the ICS exposure period. * $P<0.05$ (Significant difference between with or without C737). 
290

C. HAI-YING, ET AL.

(A) Body Temperature

$\left({ }^{\circ} \mathrm{C}\right)$

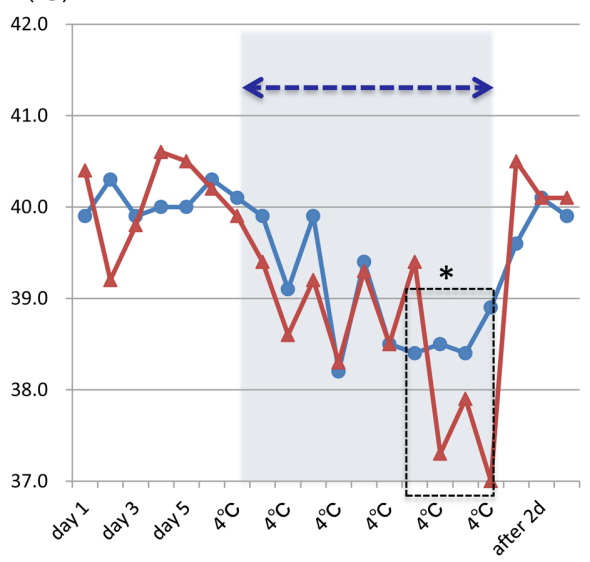

(C) Body Temperature

$\left({ }^{\circ} \mathrm{C}\right)$

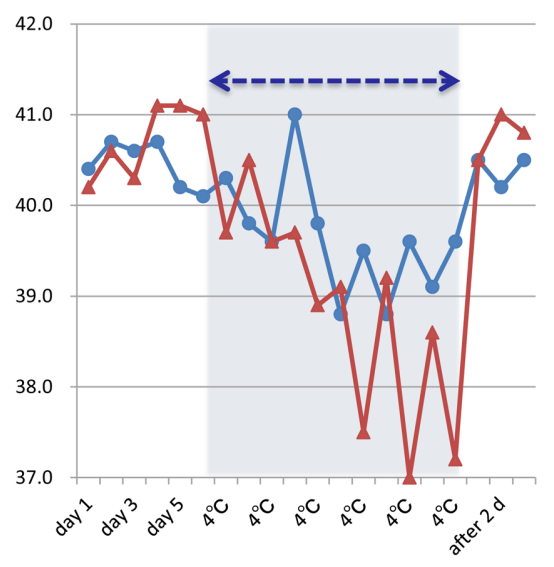

(E) Body Temperature

$\left({ }^{\circ} \mathrm{C}\right)$

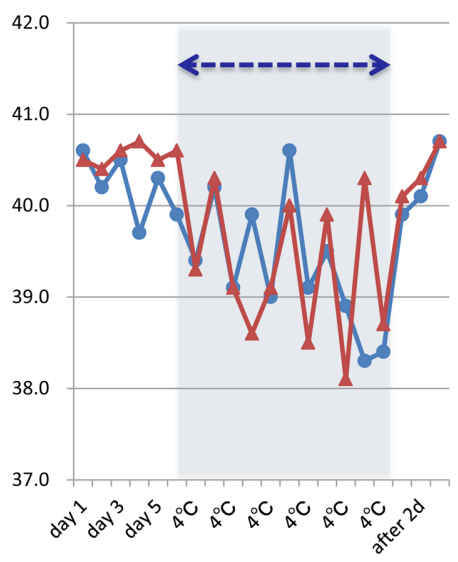

(B) Body Weight

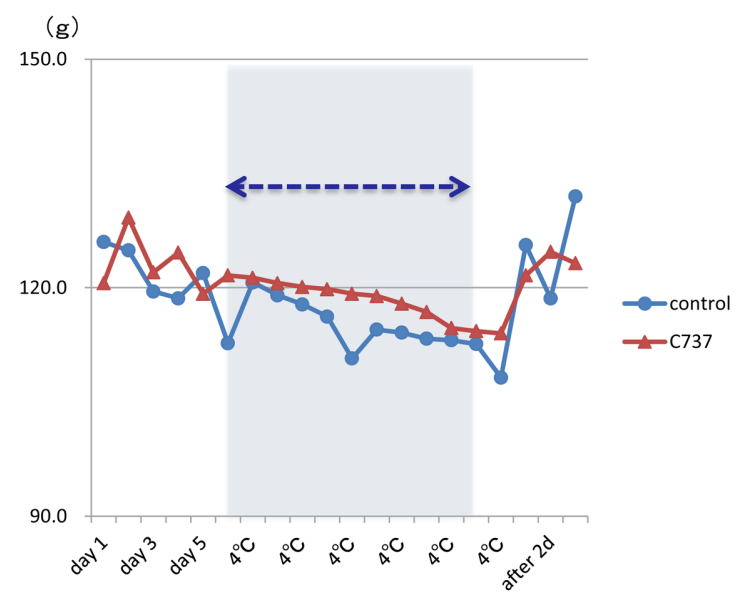

(D) Body Weight

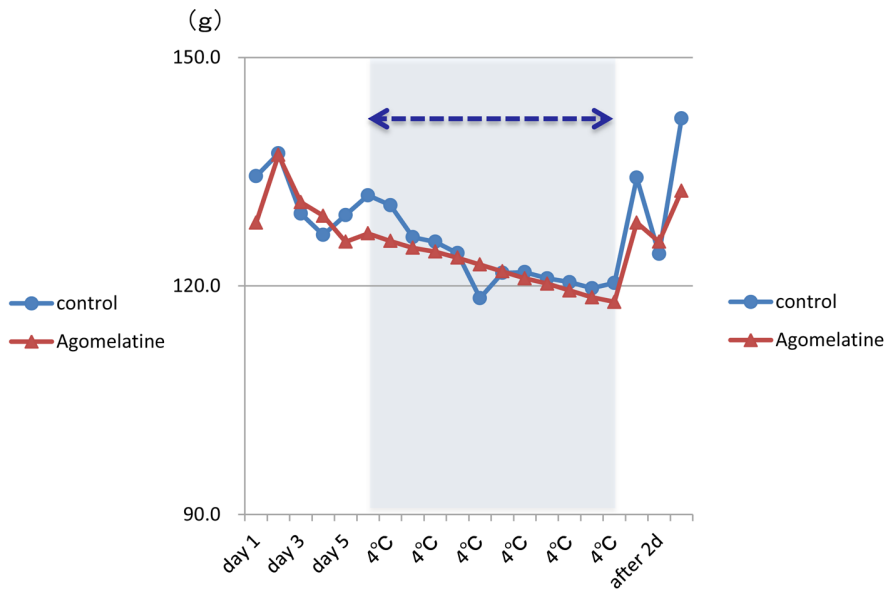

(F) Body Weight

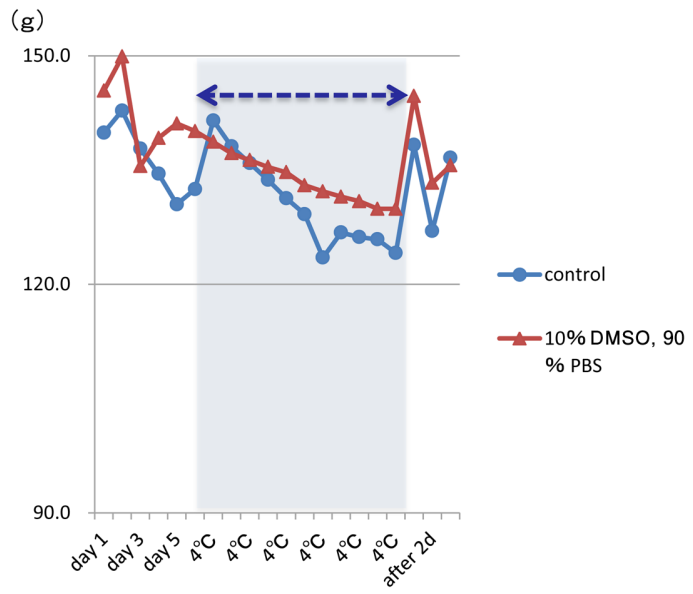

Fig. 4. Changes in body weight and body temperature in ICS-exposed male Tupaia. Body temperature (A, C, E) and body weight (B, D, F) of male Tupaia exposed to ICS with and without pre-treatment with C737 (animal No. 40; A, B), agomelatine (No. 41; C, D), or solvent control (No. 42; E, F). Shaded regions and arrows indicate the ICS exposure period. 
dopamine $\beta$-hydroxylase $[11,12])$ and receptors (e.g., the muscarinic acetylcholine receptor M4 [20, 34], the nicotinic $\beta 2$ receptor subunit [2], and the $N$-methyl-D-aspartate receptor type 1 [1]), synaptosomal proteins (e.g., synapsin I $[17,27])$, neuronal cell adhesion molecules (e.g., neuronglia cell adhesion molecule [14] and L1 [13]), neuronal cytoskeletal proteins (e.g., tubulin $\beta$ III $[3,30]$ ), neurotrophic factors (e.g., brain-derived neurotrophic factor [31]), and neuronal growth-associated proteins (e.g., SCG10 [21]). A recent study of NRSF/REST-deficient mice by Anderson and colleagues [3] revealed that the loss of NRSF/REST in vivo derepresses the expression of several of its target genes, including SCG10 and tubulin $\beta$ III. Loss of NRSF/REST disrupts neural development and ultimately leads to embryonic lethality, although the specific cause of death is unknown. Despite its prominent role in neural development, however, the transcriptional mechanisms underlying neuron-specific gene repression by NRSF/REST are largely unknown.

$\mathrm{NRSF} / \mathrm{REST}$ expression is increased in primary sensory nerve fibers after nerve disorder because of reduced histone acetylation of pain-related genes. NRSF/REST upregulation silences the expression of the $\mathrm{C}$ fibrotic desensitizing, which is a characteristic of neuropathic pain that is reported to induce morphine resistance [37]. ICS-related pain (or allodynia/hyperalgesia) could link the effects of NRSF/REST on neuropathic pain, suggesting its possible effects on ICS [37]. Compounds that bind to the paired amphipathic helix domain of $\mathrm{mSin} 3 \mathrm{~B}$, a binding partner of NRSF/REST, do not show pain inhibitory activity. Therefore, the NRSF/REST domain that interacts with $\mathrm{mSin} 3 \mathrm{~B}$, which is highly conserved among human, Tupaia and mouse, may be a potential target for new compounds. The findings of this study provide interesting non-rodent preclinical data on the effects of $\mathrm{C} 737$, a new compound that mimics the structure of NRSF/REST and can block its interaction with $\mathrm{mSin} 3 \mathrm{~b}$ and other molecules, on stress-induced abnormalities. Further studies are in progress to investigate the effects of C737 in the Tupaia induced stress model of disorders such as depression. During the course of experiment, tupaia body weight accidentally decrease by urination or evacuation in some points, therefore, evaluation of significance of drug treatment should be judged in multiple points.

In conclusion, the results of this study highlight the utility of Tupaia belangeri as a new animal model of ICS. We also show that C737 exerted protective effects against ICS-related weight loss in female Tupaia, as did the antidepressant agomelatine. Future studies are required to characterize the sex specificity of these effects and to investigate the efficacy of C737 as a novel antidepressant drug.

\section{Acknowledgments}

The authors would like to thank Mrs. Rika Matsuyama, Mr. Takumi Haraguchi, Mr. Norihiro Kanazawa, Mr. Kosuke Okuya, Ms. Hiroko Nakagawa, Mr. Kosei Ueno, and Ms. Chimene NZE for their help with animal care. This work was supported by grants from the Japan Agency of Medical Research and Development (AMED), the Ministry of Health and Welfare of Japan (H24-B-024, H25-009), and the Ministry of Education, Culture, Sports, Science and Technology of Japan (25-03079).

\section{References}

1. Bai, G., Norton, D.D., Prenger, M.S., and Kusiak, J.W. 1998. Single-stranded DNA-binding proteins and neuron-restrictive silencer factor participate in cell-specific transcriptional control of the NMDAR1 gene. J. Biol. Chem. 273: 10861091. [Medline] [CrossRef]

2. Bessis, A., Champtiaux, N., Chatelin, L., and Changeux, J.P. 1997. The neuron-restrictive silencer element: a dual enhancer/silencer crucial for patterned expression of a nicotinic receptor gene in the brain. Proc. Natl. Acad. Sci. USA 94: 5906-5911. [Medline] [CrossRef]

3. Chen, Z.F., Paquette, A.J., and Anderson, D.J. 1998. NRSF/ REST is required in vivo for repression of multiple neuronal target genes during embryogenesis. Nat. Genet. 20: 136142. [Medline] [CrossRef]

4. Chong, J.A., Tapia-Ramírez, J., Kim, S., Toledo-Aral, J.J., Zheng, Y., Boutros, M.C., Altshuller, Y.M., Frohman, M.A., Kraner, S.D., and Mandel, G. 1995. REST: a mammalian silencer protein that restricts sodium channel gene expression to neurons. Cell 80: 949-957. [Medline] [CrossRef]

5. Fuchs, E. 2005. Social stress in tree shrews as an animal model of depression: an example of a behavioral model of a CNS disorder. CNS Spectr. 10: 182-190. [Medline]

6. Fuchs, E. and Corbach-Sohle, C."Tree Shrew", p262-275 (The UFAW Handbook on the care and management of laboratory and other research animals, Hubrecht, R., \& Kirkwood, J. ed. 2010).

7. Fuchs, E., Czéh, B., and Flügge, G. 2004. Examining novel concepts of the pathophysiology of depression in the chronic psychosocial stress paradigm in tree shrews. Behav. Pharmacol. 15: 315-325. [Medline] [CrossRef]

8. Fuchs, E. and Flügge, G. 2002. Social stress in tree shrews: effects on physiology, brain function, and behavior of subordinate individuals. Pharmacol. Biochem. Behav. 73: 247258. [Medline] [CrossRef] 
9. Fuchs, E., Kramer, M., Hermes, B., Netter, P., and Hiemke, C. 1996. Psychosocial stress in tree shrews: clomipramine counteracts behavioral and endocrine changes. Pharmacol. Biochem. Behav. 54: 219-228. [Medline] [CrossRef]

10. Gupta-Ostermann, D., Hirose, Y., Odagami, T., Kouji, H., and Bajorath, J. 2015. Follow-up: Prospective compound design using the 'SAR Matrix' method and matrix-derived conditional probabilities of activity. F1000 Res. 4: 75. [Medline]

11. Ishiguro, H., Kim, K.S., and Joh, T.H. 1995. Identification of a negative regulatory element in the 5 '-flanking region of the human dopamine beta-hydroxylase gene. Brain Res. Mol. Brain Res. 34: 251-261. [Medline] [CrossRef]

12. Ishiguro, H., Kim, K.T., Joh, T.H., and Kim, K.S. 1993. Neuron-specific expression of the human dopamine beta-hydroxylase gene requires both the cAMP-response element and a silencer region. J. Biol. Chem. 268: 17987-17994. [Medline]

13. Kallunki, P., Edelman, G.M., and Jones, F.S. 1997. Tissuespecific expression of the $\mathrm{L} 1$ cell adhesion molecule is modulated by the neural restrictive silencer element. J. Cell Biol. 138: 1343-1354. [Medline] [CrossRef]

14. Kallunki, P., Jenkinson, S., Edelman, G.M., and Jones, F.S. 1995. Silencer elements modulate the expression of the gene for the neuron-glia cell adhesion molecule, Ng-CAM. $J$. Biol. Chem. 270: 21291-21298. [Medline] [CrossRef]

15. Kraner, S.D., Chong, J.A., Tsay, H.J., and Mandel, G. 1992. Silencing the type II sodium channel gene: a model for neural-specific gene regulation. Neuron 9: 37-44. [Medline] [CrossRef]

16. Kumar, S. and Hedges, S.B. 1998. A molecular timescale for vertebrate evolution. Nature 392: 917-920. [Medline] [CrossRef]

17. Li, L., Suzuki, T., Mori, N., and Greengard, P. 1993. Identification of a functional silencer element involved in neuronspecific expression of the synapsin I gene. Proc. Natl. Acad. Sci. USA 90: 1460-1464. [Medline] [CrossRef]

18. Li, Y.P., Baskin, F., Davis, R., and Hersh, L.B. 1993. Cholinergic neuron-specific expression of the human choline acetyltransferase gene is controlled by silencer elements. $J$. Neurochem. 61: 748-751. [Medline] [CrossRef]

19. Lönnerberg, P., Schoenherr, C.J., Anderson, D.J., and Ibáñez, C.F. 1996. Cell type-specific regulation of choline acetyltransferase gene expression. Role of the neuron-restrictive silencer element and cholinergic-specific enhancer sequences. J. Biol. Chem. 271: 33358-33365. [Medline] [CrossRef]

20. Mieda, M., Haga, T., and Saffen, D.W. 1997. Expression of the rat $\mathrm{m} 4$ muscarinic acetylcholine receptor gene is regulated by the neuron-restrictive silencer element/repressor element 1. J. Biol. Chem. 272: 5854-5860. [Medline] [CrossRef]

21. Mori, N., Schoenherr, C., Vandenbergh, D.J., and Anderson, D.J. 1992. A common silencer element in the SCG10 and type II Na+ channel genes binds a factor present in nonneuronal cells but not in neuronal cells. Neuron 9: 45-54. [Medline] [CrossRef]

22. Nishiyori, M., Uchida, H., Nagai, J., Araki, K., Mukae, T., Kishioka, S., and Ueda, H. 2011. Permanent relief from intermittent cold stress-induced fibromyalgia-like abnormal pain by repeated intrathecal administration of antidepressants. Mol. Pain 7: 69. [Medline] [CrossRef]

23. Nishiyori, M. and Ueda, H. 2008. Prolonged gabapentin analgesia in an experimental mouse model of fibromyalgia Mol. Pain 4: 52. [Medline] [CrossRef]

24. Nomura, M., Uda-Tochio, H., Murai, K., Mori, N., and Nishimura, Y. 2005. The neural repressor NRSF/REST binds the PAH1 domain of the Sin 3 corepressor by using its distinct short hydrophobic helix. J. Mol. Biol. 354: 903-915. [Medline] [CrossRef]

25. Owen, R.T. 2009. Agomelatine: a novel pharmacological approach to treating depression. Drugs Today (Barc) 45: 599-608. [Medline] [CrossRef]

26. Schmelting, B., Corbach-Söhle, S., Kohlhause, S., Schlumbohm, C., Flügge, G., and Fuchs, E. 2014. Agomelatine in the tree shrew model of depression: effects on stress-induced nocturnal hyperthermia and hormonal status. Eur. Neuropsychopharmacol. 24: 437-447. [Medline] [CrossRef]

27. Schoch, S., Cibelli, G., and Thiel, G. 1996. Neuron-specific gene expression of synapsin I. Major role of a negative regulatory mechanism. J. Biol. Chem. 271: 3317-3323. [Medline] [CrossRef]

28. Schoenherr, C.J. and Anderson, D.J. 1995. The neuron-restrictive silencer factor (NRSF): a coordinate repressor of multiple neuron-specific genes. Science 267: 1360-1363. [Medline] [CrossRef]

29. Schoenherr, C.J. and Anderson, D.J. 1995. Silencing is golden: negative regulation in the control of neuronal gene transcription. Curr. Opin. Neurobiol. 5: 566-571. [Medline] [CrossRef]

30. Schoenherr, C.J., Paquette, A.J., and Anderson, D.J. 1996. Identification of potential target genes for the neuron-restrictive silencer factor. Proc. Natl. Acad. Sci. USA 93: 98819886. [Medline] [CrossRef]

31. Timmusk, T., Palm, K., Lendahl, U., and Metsis, M. 1999. Brain-derived neurotrophic factor expression in vivo is under the control of neuron-restrictive silencer element. J. Biol. Chem. 274: 1078-1084. [Medline]

32. Tsukiyama-Kohara, K. and Kohara, M. 2014. Tupaia belangeri as an experimental animal model for viral infection. Exp. Anim. 63: 367-374. [Medline] [CrossRef]

33. Wolfe, F., Ross, K., Anderson, J., Russell, I.J., and Hebert, L. 1995. The prevalence and characteristics of fibromyalgia in the general population. Arthritis Rheum. 38: 19-28. [Medline] [CrossRef]

34. Wood, I.C., Roopra, A., and Buckley, N.J. 1996. Neural specific expression of the $\mathrm{m} 4$ muscarinic acetylcholine receptor gene is mediated by a RE1/NRSE-type silencing element. $J$. Biol. Chem. 271: 14221-14225. [Medline] [CrossRef]

35. Yang, A.S. and Honig, B. 2000. An integrated approach to the analysis and modeling of protein sequences and structures. I. Protein structural alignment and a quantitative measure for protein structural distance. J. Mol. Biol. 301: 665678. [Medline] [CrossRef]

36. Zheng, Y., Yun, C., Wang, Q., Smith, W.W., and Leng, J. 2015 . Identification of the full-length $\beta$-actin sequence and expression profiles in the tree shrew (Tupaia belangeri). Int. J. Mol. Med. 35: 519-524. [Medline]

37. Nishimura, Y. and Ueda, U. inventors; PRISM Pharma Co., assignee. Prophylactic or therapeutic agent for fibromyalgia. JP patent WO 2014088106 A1. June 12, 2014. 